\section{El modelo de} ancestralidad mapuche: Un debate en torno a las afinidades culturales de las representaciones escatológicas amerindias*

The Mapuche ancestrality model: A debate on the cultural affinities of Amerindian eschatological representations

\section{Rodrigo Moulian-Tesmer ${ }^{* *}$ \\ Pablo Rojas-BahAmonde ${ }^{\star \star *}$}

\section{Resumen}

El presente artículo analiza el modelo de ancestralidad mapuche y discute sus afinidades culturales respecto de otros modelos de referencia amerindios. La perspectiva teóricometodológica desde la que se aborda el tema es el análisis de las representaciones sociales. Al respecto, este trabajo plantea que la cultura mapuche dispone de un modelo de ancestralidad fuerte, que resulta afín al patrón andino. Ello se manifiesta en la presencia de los ancestros en la vida social, en la agencia y poder que se les atribuye, en los dispositivos y usos de la memoria a los muertos. El análisis del sistema de variantes de representaciones sobre la morada de ultratumba y las manifestaciones de los espíritus en la tierra evidencia, igualmente, conspicuos correlatos con respecto a las concepciones escatológicas de esta área cultural. Si bien ello no implica, necesariamente, una filiación de origen, expone la existencia de rasgos cotradicionales en las representaciones de la muerte en el espacio centro y sur andino.

Palabras clave: Ancestralidad, escatología, representaciones, mapuche.

\begin{abstract}
This paper analyzes the Mapuche ancestrality model and discusses its cultural affinities regarding other Amerindian reference models. The theoretical-methodological perspective, from which this subject is approached is the analysis of social representations. In this regard, this work suggests that the Mapuche culture has a strong ancestral model that results akin to the Andean pattern. This is evident in the presence
\end{abstract}


of ancestors in social life, in the agency and power attributed to them, and in the devices and uses of memory of the dead. The analysis of the system of variants of representations about the afterlife dwelling and the manifestations of the spirits in earth evidences conspicuous correlatives with respect to the eschatological conceptions of this cultural area. Although this does not necessarily imply a filiation of origin, it exposes the existence of co-traditional traits in the representations of death in the central and southern Andean areas.

\section{Key words: Ancestrality, eschatology,} representations, Mapuche.

\section{Introducción}

En el campo de la antropología e historia de las religiones, el concepto de 'culto a los ancestros'" designa las creencias y prácticas de veneración a los parientes muertos, consanguíneos o afines, míticos o reales, a los que se considera dotados de agencia y poder (Hardacre 1987; Long 1987; Insoll 2011). La 'ancestralidad', entendida como la presencia de los ancestros en la vida social, se expresa de manera privilegiada a través de la ritualidad y se institucionaliza por medio de la religión. Ambas forman parte de un sistema de representaciones cosmovisionarias más amplias, de carácter escatológico (Werwlosky 1987), en tanto, abordan los límites y continuidades existenciales, temporales y espaciales que se ponen en escena con la muerte. En este marco, la noción de 'ancestro' designa a los miembros del grupo social muertos que continúan siendo referentes

Siguiendo los sistemas de notación lingüísticos aquí empleamos comillas simples para distinguir la mención de un término de su uso. Las comillas dobles las reservamos para las citas textuales. importantes, a los que se invoca o recuerda ritualmente, en su condición de espíritus en la existencia de ultratumba. El grado de vigencia de las identidades personales de estos espíritus lleva a algunos autores a distinguir entre el 'culto a los ancestros' y el 'culto a los muertos'. Los primeros, situados en un pasado remoto y con identidades genéricas o difusas. Los segundos, fallecidos recientemente y con identidades personales fuertes (Clastres 1987 [1980]; Insoll 2011). En este artículo no hacemos esta distinción, preferimos aludir al grado de vigencia de las individualidades de los espíritus. La noción de 'antepasados' la empleamos como sinónimo de 'ancestros'.

En el caso mapuche, la invocación a los ancestros se ha considerado uno de los componentes distintivos de la religiosidad (Guevara 1908; Latcham 1924; Faron 1961, 1997 [1964]; Grebe et al. 1972; Dillehay 1990, 2011, 2017; Foerster 1985,1995, 2018 [2003]; Foerster y Gundermann 1989; Bacigalupo 1995a; Boccara 2007 [1998]; Moulian 2008; Moulian y Espinoza 2014; Adán 2014; Rojas 2016a y 2016b). Ello se expresa en la creencia en la continuidad de las relaciones entre vivos y muertos, a quienes desde la otra vida se les atribuye la facultad de velar por las necesidades de sus deudos (Foerster 1985; Nakashima 1992; Rojas 2013); en la propiciación ritual de los difuntos y espíritus ancestrales considerados mediadores ante las deidades y entidades con capacidad de actuar sobre las fuerzas de la naturaleza (Latcham 1924; Faron 1997 [1964]; Moulian y Espinoza 2014); y en la disposición de un sistema de normas que obliga a la práctica de la memoria hacia los antepasados, cuya contravención se considera la causa de catástrofes e infortunios, devenidos como castigos (Grebe 1975, Citarella 1995; Faron 1997 [1964]). 
No obstante, en los últimos años, autores como Course $(2011,2017)$ y Di Giminiani (2012) han cuestionado la existencia de un culto a los ancestros en la cultura mapuche, sobre la base de la generalización de su experiencia etnográfica. Sobre este tópico Course (2011: 103; 2017: 117) consigna "la ausencia de cualquier modelo elaborado por el que las almas de los muertos lleguen a un destino específico donde se conviertan en una fuente genérica de fertilidad y benevolencia". Para el autor, esta carencia de un modelo escatológico definido implicaría una desconexión entre los principios de fertilidad y ancestralidad. Si bien reconoce la importancia de los ancestros en la configuración de la identidad social de la persona, a través de küpal o líneas de descendencia, no visualiza sus componentes rituales. Di Giminiani (2012: 130) es más taxativo: "Al contrario de lo que ocurre en las tierras altas, la connotación que tienen los antepasados como fuente de poder espiritual para ser empleada por los vivos, se encuentra ausente en la sociedad mapuche", sostiene.

No es la primera vez que se plantea un debate sobre la importancia de los ancestros en la cultura mapuche. Faron (1961) le reprocha a Hilger (1957) ignorar el tema y a Titiev (1951) negarlo. Este último, por su parte (Titiev 1969), realiza una recensión crítica al libro de Faron The Mapuche Indians of Chile (1968), pero no le objeta la función estructural que le asigna al culto a los ancestros, lo que se puede entender como una concesión del punto. Los planteamientos de Course $(2007,2011,2017)$ y Di Giminiani (2012) van un paso más allá, en tanto desarrollan una argumentación tendiente a cuestionar la importancia del culto a los ancestros en la cultura mapuche. Si su posición se limitara a constatar etnográficamente la ausencia de este patrón en las áreas donde han desarrollado su investigación, no tendríamos mayor reparo. Lo discutible es su pretensión de generalización a partir de un trabajo de campo geográficamente delimitado. Como argumenta Faron (1961), ello contrariaría cuatrocientos años de acumulación de antecedentes disponibles en fuentes históricas, folklóricas y etnológicas. Lo que resulta para nosotros más inquietante es que esto no es consistente con los registros etnográficos recientes de otros sectores mapuche donde hemos trabajado.

Los planteamientos en cuestión tienen como trasfondo un debate en torno a las afinidades culturales del modelo de ancestralidad mapuche. Según afirma Di Giminiani (2012), las concepciones mapuche se distanciarían del patrón andino, marcado por el culto a los ancestros, donde los espíritus de los antepasados continúan siendo una presencia relevante en la vida de las personas tras la muerte. Para Course (2007), la funebria mapuche se propone la consumación de la persona, a través de la que se produce la exclusión entre el mundo de los vivos y los muertos. En esta ausencia de los ancestros como fuentes de fertilidad y benevolencia queda implícita la afinidad cultural mapuche con un paradigma amazónico caracterizado por la remisión de la ancestralidad (Clastres 1968; Carneiro da Cunha 1978; Clastres 1987 [1980]; Taylor 1993; Descola 2012). ${ }^{2}$ Si bien ni Course ni Di Giminiani

\footnotetext{
La validez de la generalización para la Amazonía de este modelo de disyunción entre vivos y muertos y ausencia de ancestralidad se ha discutido y matizado (Chaumeil 1992, 1997; Mouriès 2014). Lo mismo, su contraste respecto de las concepciones andinas. Nuestra referencia a este paradigma antropológico se orienta a documentar este sistema de representaciones, no supone una afirmación de la consistencia y validez del mismo, cuestión que supera las posibilidades e intereses de nuestro trabajo. Si referimos a este modelo es porque ha permeado el análisis de la ancestralidad mapuche de modo que resulta heurístico retomarlo aquí para discutir la lectura de las relaciones entre vivos y muertos en esta cultura.
} 
plantean directamente esta adscripción, su cuestionamiento de la importancia y poder de los ancestros en la cultura mapuche resultan afines a este modelo.

A partir de los antecedentes provistos por fuentes etnohistóricas, etnográficas, narrativas, lingüísticas, arqueológicas y de nuestra propia experiencia de campo, en este artículo analizamos las variantes en las concepciones escatológicas mapuche y el modelo de ancestralidad prevaleciente en esta cultura. Al respecto argumentamos que las representaciones mapuche de la muerte y el destino de ultratumba se encuentran mucho más próximas del patrón andino, donde prevalece el culto a los ancestros (Duviols 1976; Salomon 1995; Millones y Kapsoli 2001; Kaulicke 2001; Gil 2002; Bovisio 2012) que de la separación y exclusión de los ancestros de la vida cotidiana de las personas, documentado para el área amazónica. $^{3}$

Al respecto debe considerarse que, por la profundidad histórica, continuidad y extensión del culto a los ancestros, el mundo andino constituye un espacio paradigmático de ancestralidad (Isbell 1997, Doyle 1988, Eeckhout y Owens 2015, Shimada y Fitzsimmons 2015). Entre los rasgos distintivos de ésta se encuentran: 1) Elaborados procesos fúnebres que consideran: a) patrones de entierro en emplazamientos fijos que constituyen hitos en el espacio comunitario (Nielsen 2008, Norton 2013), los que en muchos casos adquieren dimensiones monumentales y emplean imágenes y elementos icónicos para representar a los ancestros (Lau 2008);

Como argumentaremos más adelante, más relevante que la distribución geográfica de los modelos es el contraste en las valoraciones de la ancestralidad que les caracteriza, marcada por la oposición presencia/exclusión de los ancestros. b) procesos que pueden incluir el tratamiento de los cuerpos para su mejor conservación (Guillén 2004) y c) la incorporación de ajuares complejos provistos para el servicio de los muertos en la otra vida (Hastorf 2003a, Peters 2014, Sánchez 2017). 2) La atribución a los ancestros de capacidad de agencia espiritual sobre el destino de sus descendientes vivos (Harris 1982, Velasco 2014, D'Altroy 2016), lo que se expresa en su capacidad de velar por las necesidades de éstos, pero también de castigar sus faltas (Aldermann 2015). 3) Prácticas rituales periódicas destinadas a la comunicación con los ancestros a través de transacciones u operaciones simbólicas (Lau 2002, Hastorf 2003b), con ofrendas, sacrificios (Ramírez 2005) y la eventual incorporación de los cuerpos de estos en las acciones performativas (Allen 1982, Arnold y Hastrof 2008, Yaya 2015), cuya interrupción genera desequilibrios y es fuente de enfermedades (Greenway 1998). 4) Un sentido de comunidad que incluye a vivos y muertos, con prácticas de sociabilidad entre éstos y marcas de identidad social y territorial que se especifican a través de estas interacciones con los ancestros (Salomon 1995, Moore 2004, Lau 2016). Para cada una de estas dimensiones se han documentado numerosas variantes, que operan en el marco de concepciones escatológicas cuyas correlaciones locales con el mundo mapuche destacaremos, progresivamente, a través del texto.

\section{Aproximación teórico-metodológica}

La perspectiva teórico-metodológica que empleamos en este estudio es el análisis de las representaciones sociales. Nuestro trabajo aborda tres ámbitos de representación de la ancestralidad: las manifestaciones 
de los espíritus personales, los derroteros escatológicos y las relaciones entre vivos y muertos. Siguiendo a Moscovici (1979) y Jodelet (1984), entendemos las representaciones sociales como estructuras de conocimiento de carácter conceptual y figurativo que conducen los procesos perceptivos y organizan la conducta humana. Las representaciones sociales son elaboraciones simbólicas de carácter convencional que modelan la realidad, organizan el pensamiento e impregnan de sentido las acciones e intervenciones sobre el mundo. Éstas se manifiestan en la comunicación, se exhiben en los discursos, pero igualmente en las prácticas simbólicas, como los rituales, en forma de contenido presupuesto que organiza el comportamiento y le da sentido. Dado que las representaciones se despliegan tanto en el habla como en la acción, nuestro registro sigue estas dos direcciones: el análisis del contenido de los conceptos que designan o se asocian a la ancestralidad y el de las prácticas vinculantes con los muertos.

La información que sistematizamos en este artículo se origina en dos vías de investigación: el trabajo de campo etnográfico y la revisión bibliográfica. El primer autor ha realizado trabajo de campo etnográfico en comunidades mapuche williche de las comunas de Lago Ranco y Río Bueno, abocado al estudio de las prácticas rituales (Moulian y Valdés 2001; Moulian 2005, 2008, 2012), por espacio de diez años, entre 1998 y 2008. Su experiencia etnográfica comprende además las áreas de San Juan de la Costa (Región de Los Lagos) y Mariquina, Lanco y Panguipulli (Región de Los Ríos). Su trabajo se concentra, particularmente, en el estudio de las ceremonias comunitarias conocidas genéricamente como ngillatun y la visita a la morada de los ancestros tutelares de las comunidades. A partir del año
2012 y hasta el presente, ha venido realizando trabajo de campo focalizado en prácticas rituales en el espacio central andino, especialmente en las zonas de Tacna, Cusco, Puno (Perú) y Copacabana y La Paz (Bolivia). El segundo autor ha desarrollado una investigación etnográfica focalizada en prácticas funerarias en los sectores de Lago Neltume y Punahue (Rojas, 2013; Rojas et al. 2015; Rojas 2016a y 2016b), emplazados en el área precordillerana de Panguipulli (Región de Los Ríos), desde el año 2010 hasta la actualidad. El trabajo de ambos investigadores considera la observación participante recurrente en prácticas rituales, el estudio de los espacios y geografías simbólicas en los que se inscriben estas prácticas, la entrevista a informantes calificados para la comprensión y contextualización de las mismas.

Ambos autores han realizado una revisión sistemática de la bibliografía sobre el tema considerando fuentes etnohistóricas, estudios protoantropológicos, narrativas étnicas, fuentes lingüísticas e investigaciones etnográficas sobre la concepción mapuche de la muerte, los patrones fúnebres, las concepciones escatológicas y las relaciones entre vivos y muertos. Como principios metodológicos en la gestión de la información hemos empleado la triangulación de datos y fuentes y la validación de las generalizaciones emergentes de su interpretación por parte de informantes calificados.

\section{Transformaciones del espíritu}

Las voces liwe, neyen, püllu, am, alwe, pillan ${ }^{4}$ sirven en mapudungun para designar a las manifestaciones anímicas de las personas en el

Para la escritura de los términos mapuche empleamos el Alfabeto Mapuche Unificado, salvo en el caso de las citas textuales en las que se preserva la forma de escritura empleada por las fuentes. 
devenir entre la vida y la muerte. Los esfuerzos de los investigadores por analizar este sistema de categorías enfrentan dos dificultades: la superposición en las definiciones y la variabilidad de sus usos. No obstante, el acervo lingüístico informa la importancia que se le asigna a los distintos estados y transformaciones del espíritu y, por su presencia en los repertorios del lenguaje ritual, registra la vigencia del culto a los ancestros.

El término 'alwe', por ejemplo, denota al muerto (Valdivia 1887 [1606]: sp; Febrés 1765: 426; Augusta 1916), a su cuerpo inerte (Marileo 1995: 106), al ánima del muerto que anda penando tras su deceso (Moesbach 1980: 22) que Erize (1960: 49) caracteriza como un "ente intangible y vaporoso" que aparece en el instante de la muerte, "se incorpora a su cadáver y lo acompaña hasta la tumba". No obstante, el término también se emplea para designar a los espíritus que han traspasado el umbral de la otra vida. A éstos se los invoca en las oraciones rituales williche que se enuncian en las rogativas con la expresión ' $p u$ alwe'. Al respecto apunta Foerster (1985: 55): "con este término se invoca a las almas de los antepasados". De acuerdo a un testimonio que cita el autor, de esta forma "se ruega [...] a los muertos que se han ido, se cree que allá están felices y que pueden interceder por nosotros, por los vivos" (ibid.).

El sentido de la voz 'am' se superpone con la anterior. Según Febrés (1765: 428), ella denota al fantasma, bulto o sombra o ánima. Es el cuerpo invisible que se levanta en el momento de la muerte, señala Marileo (1995). De acuerdo a Erize (1960), es el espíritu del muerto, que acompaña al cadáver y permanece junto a los suyos a través de sus recuerdos.
Para este mismo autor, la expresión 'pu am' que pronuncian los mapuche desde tiempos inmemoriales antes de comer y beber es una reminiscencia del culto a los antepasados. Rosales (1877: 162) da testimonio de esta costumbre:

en sus casas cuando almuerzan y beben el primer jarro de chicha meten primero el dedo y asperjan (como quando echamos agua bendita) a sus difuntos diziendo pu am que es como brindando a las almas...

El término 'püllu' es, probablemente, el de uso más frecuente en el campo de las manifestaciones anímicas, puesto que designa al espíritu de las personas en vida (Catrileo 1995; Zúñiga 2004) tanto como en su estado y lugar definitivo, tras la muerte (Latcham 1924; Moesbach 1980; Erize 1960). Por su relación con los individuos, Course (2011: 115) lo caracteriza como "núcleo interior único del ser". No obstante, Bacigalupo (2016) muestra la posibilidad de que éste asuma un carácter transpersonal, por su capacidad de encarnar en diversas personas, como sucede en el caso de los chamanes mapuche o machi que trabajan con diversos püllu.

La voz 'pillan' presenta un amplio registro en el vocabulario de las prácticas rituales colectivas, donde se encuentran términos como 'pillankushe', 'pillankutral', 'pillankura'. Según Latcham, esta voz que los cronistas y lexicógrafos coloniales atribuyeron a un numen emplazado en los volcanes, corresponde a los antepasados. Moesbach (1980) plantea que se trata de un término polisintético, generado de la fusión de las voces 'püllu' y 'am' en las que se expresan las concepciones animistas mapuche. En el vocabulario chamánico que registra Bacigalupo (2007), 'pillamtum' es la rogativa a los espíritus y los 'püllu am' son los principales guerreros espirituales a los que acuden las machi. 
El término 'neyen' designa 'resuello', 'hálito' (Augusta 1916: 147). Según Marileo, es 'soplo' (en Foerster 1995: 64), término que también usa como sinónimo de espíritu (Marileo 1995: 106). En tanto, la voz 'liwe' denota 'vida', 'aliento', 'valor' y 'espíritu' (Febrés 1765: 412), 'vigor de ánimo' (Havestadt 1883 [1777]: 696). En términos de Erize, "es el espíritu que se manifiesta (...) en el brillo de los ojos: su ausencia deja opaca las pupilas e indica la muerte" (1960: 221).

La multiplicidad de voces y la diversidad de sus usos, que aquí consignamos parcialmente, no implica de suyo que los mapuche tengan una idea difusa de las manifestaciones del espíritu, sino que sus concepciones se presentan en sistemas de variantes. Ellas tienen diferentes formas de concreción en distintos espacios territoriales y difieren según las competencias y modelos de referencia de los portadores. En muchos casos los modelos se encuentran claramente cristalizados, como expresa el longko José Quidel:

Tras la muerte se separan las partes que constituyen al hombre. (...) Parece haber acuerdo en que hay siempre tres constituyentes: la carne que queda en la tierra, la imagen que queda en el lof durante unos meses y en el recuerdo después, y el espíritu que viajará a otras tierras (Quidel y Pérez 2001: 163 y 164).

De acuerdo a esta fuente, una terminología bastante aceptada es que el alwe corresponde a la carne, el am al cuerpo invisible y el püllu al espíritu de la persona que tras la muerte emprende un viaje a la otra vida y vela por los que quedan en la tierra. De modo similar lo plantea el ngenpin Armando Marileo. Según este kimche (sabio mapuche), el ser está compuesto por tres elementos: el alwe, cuerpo inerte; el am, imagen o retrato y el püllu, espíritu. En sus palabras:
Cuando alguien muere el am queda en el recuerdo de las personas como imagen. Durante un tiempo también queda viviendo como el otro yo de la persona y luego desaparece. El püllu se va en forma invisible; sigue viviendo en la eternidad, representando a la persona en toda la magnitud (Marileo 1995: 106).

Valderrama y Escalante (1980: 252) registran, etnográficamente, un modelo similar en el área central andina. De acuerdo a los testimonios aportados por los autores, los comuneros de la comunidad de Awkimarka, Apúrimac, distinguen tres almas: el alma mayor, "que se va al Apo Qoropuna" (el volcán más alto de la región); el alma del centro "se queda para toda la eternidad en nuestra sepultura, junto a nuestro cuerpo". El alma menor "a nuestra muerte da vueltas en nuestra casa, en nuestro pueblo", pero luego, cuando es "arreada" se junta con el alma mayor en el Qoropuna.

\section{Derroteros escatológicos}

Los patrones funerarios mapuche informan que en esta cultura la muerte presupone la continuidad de la existencia del espíritu. Por lo mismo, el cadáver se entierra junto a alimentos y bebidas depositados en cántaros, además de la ropa y pertenencias más valiosas del difunto. El paso a la otra vida asume un carácter progresivo, puesto que se considera que el espíritu debe emprender un viaje que lo conduce hacia su morada definitiva. De acuerdo a los informantes de Nakashima (1992), la duración del peregrinaje oscila entre uno y cuatro años. Estos datos coinciden con las concepciones de la muerte de comunidades quechua y aymara, donde las almas caminan hacia la otra vida en un periplo que puede durar cuatro años. Por lo mismo, los deudos deben acompañar ritualmente a las almas frescas durante el Día de los Muertos los tres primeros años consecutivos 
a su fallecimiento, puesto que recién entonces ellas acceden a su residencia definitiva. ${ }^{5}$

Uno de los rasgos distintivos de las representaciones mapuche sobre el lugar de vida de ultratumba es su variabilidad fenomenológica. No se trata de un fenómeno exclusivo de este ámbito religioso. Algo similar ocurre en los rituales propiciatorios colectivos conocidos genéricamente como ngillatun, que exhiben notorias variantes en los patrones simbólicos y el diseño de las canchas rituales (Moulian 2012). También, con las prácticas chamánicas de las/ los machi que manifiestan modelos operativos y cosmovisionarios diversos (Bacigalupo 1995b).

Esta variabilidad es propia de las culturas 'gramaticalizadas', según la conceptualización de Lotman y Upenski (1979), que es el modo de producción semiótico distintivo de las culturas orales, como la mapuche. En ellas, las prácticas culturales resultan de la puesta en juego de reglas de operación generales en contextos específicos, siempre cambiantes, lo que produce series de transformación en los enunciados a partir de principios generativos comunes. Lo que los sujetos de la enunciación manejan son reglas de producción que se emplean contextualmente para ajustarse a las necesidades del caso, desplegando rasgos estilísticos identitarios particulares. Los patrones textuales, por lo tanto, son siempre variantes. El juego de posibilidades múltiples en el plano de la expresión da lugar a lógicas no lineales en el plano de la representación (Kemper 1997), donde las concepciones alternativas no se excluyen, sino se complementan, coexisten

Datos emergentes de nuestro trabajo etnográfico para el Día de Todas las Almas en los cementerios de Azapa (Arica), Pocollay, (Tacna, año 2013), Yanamayo, Chucuito, Acora (Puno, año 2014), El Alto y General (La Paz, año 2016). y/o alternan posiciones en los relatos, como veremos más adelante, lo que da lugar a una topología escatológica no solo variable, sino multisituada.

Respecto de los espacios escatológicos en la cultura mapuche, se registran tres destinos predominantes definidos: nomelafken (el otro lado del mar), dewiñ (los volcanes) y wenumapu (el cielo). Las representaciones de cada uno de los mismos se expresan en un sistema de variantes y se encuentran relaciones de continuidad y transformación entre ellos. Esta variabilidad ha sido documentada por cronistas (Rosales 1877; Molina 1795), investigadores (Guevara 1908; Latcham 1924; Cooper 1946), estudiosos del lenguaje (Moesbach 1980; Erize 1960), especialistas en narrativas (Slater 1986; Vásquez 1988; Delgado 2001; KoesslerIlg 2006), antropólogos (Faron 1997 [1964]; Foerster 1995; Montecino 1997; Rojas 2016b) y etnohistoriadores (Silva 1980; Véliz 1996). En el espacio central andino se encuentra una diversidad de espacios escatológicos equivalentes y un sistema de variantes semejantes, que identifican el otro lado del mar, los volcanes y el cielo como destinos definitivos (Arriaga 1621; Valderrama y Escalante 1980; Negro 1996; van Kessel 1999; García 2009; Millones 2010).

La concepción más extendida es la que identifica al nomelafken, el otro lado del mar, como el espacio de ultratumba. También se la conoce como külchemapu o kül-che maihue, la tierra de las entrañas y, en la costa de Arauco, se la identifica con la Isla Mocha. Antecedentes de esta creencia se encuentran en el área costera entre las regiones del Bío-Bío y de Los Lagos, desde Tirúa al sur de Chiloé. En el área lelfunche o de los llanos en la cuenca del Río 
Bueno, donde hemos desarrollado un extenso trabajo etnográfico, ha sido la representación predominante en el pasado. Así lo advierte Salvador Sanfuentes (1925: 143), un antiguo intendente de Valdivia:

Los araucanos ponen las sepulturas de sus muertos a la orilla de algún arroyo para que la corriente conduzca el alma a la tierra de las almas, que algunos creen ser la isla de la Mocha.

En este espacio, los cementerios se sitúan habitualmente en las riberas de los ríos o en las inmediaciones del afloramiento de vertientes subterráneas, para que los espíritus viajen por sus aguas (Millahueique 2003). Sobre este tema, un ngenpin del área de Loncoche nos explicó que los espíritus se mueven hacia "el lugar donde van las aguas", designado 'amunkowe'. El uso del wampo o canoa como contenedor fúnebre da testimonio de este modelo. Con este nombre se conoce al tronco de árbol ahuecado para servir de cofre mortuorio, el que se cubre con tapa labrada de madera nativa (Moesbach 1936 [1930]; Housse 1940: 328). La expresión popular "creerse la muerte en bote" refiere a la costumbre de ataviar a los muertos que se ponen en el wampo con sus mejores prendas. El registro arqueológico más antiguo de este patrón fúnebre arroja una datación con radiocarbono de 1280+-80 DC (Gordon 1978).

En las creencias mapuche, la canoa es uno de los medios para pasar a la otra vida (Guevara 1908; Cooper 1946; Koessler-llg 2000 [1954]; Curaqueo 1989-1990; Bengoa 2003), el nontufe o balsero es el porteador que conduce hacia la morada de ultratumba y cumple funciones de portero (Montecino et al. 2003). En ocasiones los seres en tránsito se mueven caminando o a caballo hasta un cuerpo de agua donde deben ser balseados. El pago para acceder a la otra vida se realiza con unas piedras de color verde azulado, llamadas Ilanka, contenedoras de silicato de cobre, que tienen en alta estima. En el litoral marítimo, el paso al destino final lo realizan ballenas llamadas 'trempulkalwe', término que significa 'portadoras de almas' (trem-pu-ka- alwe). El mito del 'kaleuche', barco fantasma, expresa la posibilidad del viaje en sentido inverso (Koessler-llg 1962). Etimológicamente, el término significa 'gente del otro río' o, podríamos decir, 'gente del otro lado del río'.

El movimiento de las almas mapuche hacia el poniente sigue los pasos del sol. Del mismo modo sucede en el mundo andino, donde la morada de ultratumba también se identifica con un espacio allende el mar. Así lo registra el padre Arriaga en su Extirpación de la Idolatría del Piru (1621: 41):

Otros tienen por tradición que las almas de sus defuntos van donde están sus Huacas. Los del pueblo de Huacho, y otros de la costa, dizen que van a la Isla de Huano y que los llevan lobos marinos que ellos llaman Tumi.

Algunas piezas de la iconografía y cerámica moche registran estas representaciones escatológicas marinas (Makowski 2000; Bourget 1994; Fernández 2009). Millones (2010: 132) señala la vigencia de esta idea en la costa norte del Perú:

En esta zona que es el espacio de Mórrope, el tumi (lobo de mar en muchik) es quien lleva en su lomo a las almas de los fallecidos, a través de las aguas marinas, hacia las islas que se aprecian desde la orilla.

No obstante, como muestra Quidel (2012), más que un lugar específico, el lafkenmapu señala en la cosmovisión mapuche una dirección. Ésta se encuentra marcada por el movimiento solar (Fu 2016). Su trazado conecta los cuerpos de 
agua con el wenumapu, la tierra de arriba, que se identifica, igualmente, como destino de los muertos. Latcham (1924) pensaba que la alusión al cielo era resultado de una influencia cristiana. A nuestro entender, hay suficientes antecedentes para señalar el origen ancestral de esta concepción. Así lo muestra el relato mítico Los antepasados celestes de los araucanos (KoesslerIlg 2000 [1954]: 79-80). Éste recuerda el origen sideral de los seres humanos nacidos de las estrellas. Según el mismo, los astros que pueblan el firmamento son la manifestación de las almas de los muertos en el retorno a su lugar de origen.

La voz wenuleufu, que significa 'río de arriba', designa en mapudungun a la Vía Láctea. El término muestra la continuidad entre los planos de la tierra y el cielo, que se reflejan mutuamente. Así como las almas navegan por los ríos de la tierra, en el río de estrellas se identifica a los espíritus en su viaje a la morada eterna, ubicada en el wenumapu. La Vía Láctea se presenta como un rüpu, camino por donde transitan las personas fallecidas (Pozo y Canio 2014). Del mismo modo lo refiere "La leyenda del fuego" (Amory 2013: 225):

Los Mapuches creían que sus antepasados revivían en la bóveda del cielo nocturno. Cada estrella era un antiguo abuelo iluminado que cazaba avestruces entre las galaxias.

El ragnin wenu, 'cénit' o 'región celeste', es otra expresión que nombra a este destino (Schindler 1996). Así también lo señalan las oraciones registradas por Augusta y Fraunhaeusl (1910: 34):

¿Chemngetuimn chey mün femiawü? / Regiñwenu ngetuin chey? / Antüpayñamkungetuim? / Antükütrükütrümgeimn? / Antükullengkülleng ngeimün femrupaiawün?

(¿En qué os habéis convertido en vuestro tránsito? / ¿Os habéis hecho seres de la región del cénit? / ¿Os habéis hecho águilas del sol? / ¿Os habéis hecho Peucos del sol? Os habéis hecho cernícalos del sol?)

Como apunta Faron (1997 [1964]: 9), los pájaros son una representación de los ancestros. La pregunta “¿antupaiñamko ngentuiñ?” (“¿has pasado a serun halcón del sol?") es una expresión retórica que simboliza la transformación espiritual de los antepasados en su tránsito hacia el wenumapu. Esta transfiguración ornitomórfica también es señalada por Guevara (1911). Augusta y Fraunhaeusl (1910: 29) les atribuyen el papel de mediadores: "los espíritus convertidos en pájaros llevan la denominación de pájaros del sol, porque allí se detienen, cerca del Ng' nechen y desde allí prestan auxilio a los hombres".

Esta asociación entre aves y ancestros se encuentra presente, igualmente, en el mundo andino, donde se identifica a los cóndores con los espíritus de los que han pasado a la otra vida (Abercrombie 1998; Urton 2006: 40). La vinculación de los mismos con el río de estrellas se hace explícita durante el Día de Todas las Almas, cuando las personas se reencuentran con los muertos. La fecha de esta celebración, el 2 de noviembre, coincide con el posicionamiento de la Cruz del Sur en el punto más cercano al horizonte. En la cultura aymara persiste la idea de que para esta fecha las almas caminan por el río celeste y bajan al mundo a través de la chakana, como se denomina a la constelación de la Cruz del Sur, que constituye un puente de estrellas (Moulian y Garrido 2015). En la cosmovisión atacameña, ello es aún más explícito, porque los muertos deben atravesar con sus perros el río de las estrellas para llegar al otro mundo (Cruz et al. 2013).

En cambio, en el espacio mapuche precordillerano, los volcanes se consideran como 
la vía de acceso o bien morada definitiva de la otra vida. Esta concepción se encuentra activa en las comunidades del área de Lago Neltume y Punahue (Rojas 2013) y Lago Calafquén, que ven al volcán Villarrica, denominado en mapudungun 'Rukapillan', que significa "la casa de los espíritus" (Grebe 1986), como el lugar hacia donde van sus muertos. Esta característica distintiva de los volcanes los sitúa como uno de los componentes ineludibles para comprender las formas de habitar en la zona, tanto pretéritas como actuales (Alvarado y Mera 2004). En la vertiente oriental de Los Andes, las comunidades puelche han reivindicado el carácter sagrado del volcán Lanin, aludiendo a su función como derrotero escatológico. Etimológicamente el nombre de este volcán se ha interpretado como 'Lalin' que significa la 'roca de la muerte', pero nos parece que es más próximo y apropiado leer el término como 'Lanün', contenedor de la muerte, donde muerte es 'la' y 'nün' coger, agarrar, recibir (Augusta 1916).

En el área central andina, el volcán Qoropuna, la tercera montaña más alta de Perú, ubicado en la Provincia de Arequipa, igualmente es considerado "la puerta de entrada al país de los muertos" (Arguedas 2012: 286). Las primeras referencias sobre este destino escatológico las provee Guaman Poma de Ayala (1980: 209): “los Collasuyu Condesuyu se van los difuntos derecho a Puquinapampa y Coropuna". Valderrama y Escalante (1980) registran etnográficamente la vigencia de estas representaciones en el área de Apurimac. De acuerdo a los comuneros, al interior del volcán se encuentra un gran pueblo provisto de innumerables calles con sus casas donde se van a vivir las almas de los muertos.

Del mismo modo sucede en la narrativa oral mapuche del área de Calafquén (Calvo 1987;
Kuramochi y Huisca 1997; Yanai 2004) que identifica al volcán como la residencia espiritual de los difuntos. Calvo (1987), por ejemplo, registra la historia de un hombre que en el límite de la muerte emprende el viaje hasta el Rucapillán y se reencuentra allí con sus familiares. Yanai (2004: 157) documenta el viaje onírico de un ngenpin quien entra en la montaña para encontrarse con la morada de sus antepasados míticos, pillan fucha y pillan kushe quienes hacen las veces de mediadores ante la divinidad. Según el testimonio que recoge el autor,

\footnotetext{
... ahí están los viejitos, hay mujeres, con puros pañolones azules, todos a patas. Y el viejito, dueño del volcán, un veterano amarrado de cabeza, blanco el pelo con una manta rayada, y con su asiento. Gentes ancianas, y gente nueva también [...] Tienen sus animales, sus potreros, todas clases de animales. El potrero mayor donde están todos los animales es del dueño del volcán.
}

Un punto relevante de destacar es el diálogo entre estas representaciones escatológicas alternativas. En Maihue-Carimallín y Nolguehue, comunidades lelfunche de la comuna Río Bueno, donde prevalece el patrón fluvial-marino, el volcán Osorno es un elemento integrado al paisaje simbólico. Los cementerios de estas localidades se ubican a la vera de ríos que conducen a los espíritus hacia el mar. Ambos, no obstante, se emplazan en sitios que tienen una vista privilegiada del volcán. Las variantes dewun-lafken forman parte de un sistema integrado, que muestra las alternativas. En este espacio los volcanes se conectan con los lagos que desaguan por los ríos que van al océano (Skewes y Guerra 2016). Esta lógica relacional e inclusiva se manifiesta en una forma de pensamiento no lineal, que podemos llamar modular, pues pone en escena distintas opciones en juego en paralelo. Los discursos de cantos y oraciones fúnebres muestran esta misma lógica: 
En el balseo me ayudarán, son cuatro las trempulkalue. Pondrán un puente y me será fácil pasar, con la treua negra, por el camino que siguieron los abuelos. No caeré en el cráter [...] (Koessler-Ilg 2006: 65).

No hay mucha distancia entre la vida y la muerte. El camino, el puente que lleva del 'mundo de abajo' hasta el Kallfu Uenu es más corto que el camino de aquí hasta abajo. Así es entre la vida y la muerte (Koessler-Ilg 2006: 67).

Estos versos, que en primera instancia oponen las variantes mar-volcán, integran luego al wenu mapu (llamado aquí 'Kalfu Unenu'), mostrando un sistema de relaciones y continuidades no lineales, sobre la base de desplazamientos paradigmáticos. Lo mismo podemos ver en registro etnográfico de Lago Neltume, donde los espíritus se asocian al volcán, se los visita en el cementerio y se los identifica con los árboles de los espacios que han servido de descansos fúnebres. Otro tanto ocurre en Calafquén donde a los ancestros se los sitúa en el Rukapillan tanto como en el kamarikuwe, cancha ceremonial. Esta topología plural identifica los lugares de tránsito y desplazamiento de los espíritus desde y hacia el otro mundo como espacios de presencia espiritual, lo que plantea una localización múltiple.

La variabilidad de las representaciones escatológicas previamente reseñada no es un rasgo exclusivo del mundo mapuche. Del mismo modo ocurre en el espacio andino. El registro etnohistórico (Arriaga 1621; García 2009; Negro 1996) y etnográfico (van Kessel 1999) explicita una diversidad de localizaciones del lugar donde van las almas. Aquí también hay quienes han caracterizado a estas concepciones como difusas (Bascopé 2001). No obstante, estos rasgos no constituyen un impedimento para el funcionamiento en esta área del culto a los muertos.

\section{Relación con los ancestros}

Amulpullun es el nombre que recibe el ritual fúnebre mapuche abocado a asegurar la partida del espíritu del difunto, evitando que éste sea capturado por los brujos y fuerzas negativas y se vuelva un peligro para sus consanguíneos y afines. Se compone de discursos realizados por representantes de las ramas bilaterales de parentesco del fallecido y ofrendas de despedida. Como señala Course (2007), el amulpullun asume un carácter sintético, en tanto supone una articulación del campo de las relaciones sociales de la persona y opera su consumación, por cuanto presume el término de la misma y su paso a una nueva dimensión. No obstante, a diferencia de lo señalado por este último autor, plantemos que en la cosmovisión mapuche ello no supone el término de su sociabilidad, porque las relaciones entre las personas vivas y los espíritus de los difuntos se mantienen tras la muerte (ver Rojas 2016a). El carácter articulante de la historia y relaciones sociales de la persona que se despide enfatiza su identidad personal, que se mantiene tras la muerte. Al igual que en el mundo andino, entre ellos prima el principio de reciprocidad (Fernández 2007). Los vivos recuerdan y ofrendan alimentos y bebidas a los muertos, éstos velan por la satisfacción de las necesidades de sus deudos. En este sentido, coincidimos con lo planteado por Foerster (1995: 89) para quien las exequias mapuche tienen como objetivo "hacer del muerto un verdadero muerto, un antepasado".

Uno de los espacios donde se expresa esta sociabilidad es en los rituales comunitarios conocidos genéricamente como ngillatun. En la comunidad de Witag, próxima al Lago Calafquén, la práctica de visitar el cementerio o eltun previo a la realización de estas rogativas para invitar 
a los difuntos, se denomina "chalinfünün" (Kuramochi y Nass 1989: 35; Kuramochi y Huisca 1997: 300). Ésta se encuentra, igualmente, vigente en las congregaciones de las áreas de Panguipulli (Rojas 2016a), bajo la denominación de chalilelfun. Una manifestación elocuente de esta práctica la observamos en el eltun del Lago Neltume, que se mantiene en uso sólo para fines rituales, porque su capacidad para acoger cuerpos se encuentra superada. La visita para invitar a los difuntos es también aquí el punto de partida del ngillatun.

En el espacio lelfunche de Lago Ranco y Río Bueno, los espíritus se asocian a las fuerzas de la naturaleza. Cuando las tormentas que ingresan desde la costa traen truenos y relámpagos, se dice que son los 'kiluche' o külche, gente de la tierra de las entrañas. Para aplacar sus manifestaciones, la gente echa trigo o harina tostada a los braseros para alimentar a los espíritus (Moulian 2012). En las rogativas de esta área, existe la creencia de que los vientos que se sienten apenas plantan los primeros estacones del rewe son los 'katriwanos', gente de Pucatrihue. De este modo denominan a las almas que vienen desde el mar para hacerse presentes en la rogativa (Moulian 2005). En la rogativa de Litrán hemos visto el uso de velas en memoria de miembros de la congregación ritual difuntos. Como señalan Faron (1961) y Yanai (2004), hay comunidades donde se considera que los espíritus de los muertos moran en las canchas de rogativa. El acto ritual denominado 'yapepellun' procura su animación para que se incorporen a las ceremonias (Kuramochi y Huisca 1997: 312-313). Con este mismo sentido lo hemos observado en una ceremonia de La Paz.

Las oraciones de las rogativas williche de San Juan de la Costa apelan directamente a los espíritus, bajo la fórmula pu alwe. En el área de Lanco-Panguipulli es habitual que los encargados de las oraciones mencionen en el discurso ritual a las personas que forman parte de su meli kupal. En esta área se mantiene vigente la figura del ngenpin, literalmente, dueño de la palabra, título que reciben los sacerdotes mapuche. Éstos trabajan con los espíritus de los ancestros míticos y reales, quienes se comunican a través de sueños y visiones. En nuestra experiencia de trabajo de campo en el área, la referencia y apelación a los püllu es una constante en las discusiones políticas y decisiones comunitarias, pues éstos son quienes dan las pautas y orientaciones de conducta.

No obstante, la vigencia del culto a los ancestros en las ceremonias comunitarias se encuentra en retroceso. Por lo mismo, se entiende que los resultados del trabajo etnográfico de autores como Course $(2011,2017)$ y Di Giminiani (2012) señalen su ausencia. Melville (2016 [1976]), realizó trabajo etnográfico entre 1973 y 1975 en la Provincia de Cautín, ya había destacado la falta de un culto a los ancestros en las rogativas. Entendemos, como argumenta Bacigalupo (1995a), que los procesos de transformación histórica de la sociedad mapuche permiten explicar esta situación. En la medida en que el sistema de organización fundado en vínculos de linaje da paso a formas de organización social ampliada multilinaje, el culto a los ancestros reales deja de tener efectos cohesionantes.

Una solución intermedia a este problema es la apelación a ancestros míticos que asumen un carácter generalizado. Esto se puede ver en el área lelfunche de Lago Ranco y Río Bueno donde se rinde culto a espíritus mediadores emplazados en el espacio, como Kintuantü, Juanico y Wenteyao, considerados ngen mapu, 
dueños del territorio. El último de estos espíritus asume un carácter regional, porque es invocado en San Juan de la Costa, en el área cordillerana de la Provincia del Ranco y al sur de Chiloé.

Como expresión de este culto a los ancestros míticos, en el área lelfunche las rogativas se encuentran precedidas por la visita a la casa de estos espíritus mediadores, para invitarlos a las ceremonias. En Nolguehue y Maihue Carimallín, los comuneros recogen ramas de laurel como elementos significantes de los mismos y las colocan en los rewe para alimentarlas con sangre de los animales sacrificados y muday. A estas 'ramitas' las llaman 'el caballito', porque plantean, que los espíritus van montados sobre ellas. Al finalizar las ceremonias, serán devueltas a la morada de los espíritus, para cerrar el ciclo ritual (Moulian $2008,2012)$. Otras formas de superar los límites del kupan o principio de filiación, que sustente el culto a los ancestros, son la veneración de los espíritus de la naturaleza o la invocación directa a las deidades. Ambas son formas de expresión cúlticas ampliamente extendidas en La Araucanía en la actualidad.

No obstante, incluso donde se ha producido este desplazamiento de los rituales comunitarios, la relación con los ancestros se mantiene en el plano personal, a través del ejercicio de la memoria, las solicitudes individuales, la comunicación a través de los sueños y las ceremonias familiares. Como advierte Erize (1960), los espíritus se mantienen en el nagmapu a través de la memoria de los deudos. Por lo mismo, en los funerales se impone entre los asistentes la prohibición de mencionar el nombre del muerto, como una forma de facilitar su partida. Sin embargo, una vez que se ha asegurado su desprendimiento de este mundo, los deudos retoman su sociabilidad con los espíritus. ${ }^{6}$

Una forma privilegiada de comunicación de los mapuche con los ancestros es el sueño o pewma. La misma se encuentra documentada, igualmente, en el mundo andino (Robin 2008, Cecconi 2013, Vargas 2013, La Riva 2017). La experiencia onírica se considera aquí un viaje en el que el alma se desprende del cuerpo y puede encontrarse con los espíritus o los dioses.

Del mismo modo ocurre en el conocimiento mapuche. El sueño es un estado en el que el am se desprende del cuerpo y viaja por las diversas dimensiones del mundo (Nakashima 1989; Ñanculef 2016, Quidel 2017). Durante estos desplazamientos, los protagonistas pueden encontrarse con los püllu de sus ancestros. A la inversa, igualmente, los sueños son considerados una vía a través de la cual los espíritus se hacen presentes en el mundo para relacionarse con sus deudos (Faron 1997 [1964]). Según Nakashima (1992), este tipo de experiencia es de las más importantes para los mapuche. En el registro de las narrativas oníricas que provee esta autora, los püllu sirven de guía a los soñantes en su viaje al wenu mapu, les anuncian acontecimientos futuros y auguran castigos a quienes han abandonado las normas. En sus palabras (1992: 49):

\footnotetext{
Los sueños actúan como el vehículo de contacto que está constantemente recordando a los mapuche que la muerte no es la etapa final de la vida sino una etapa de transformación la cual integra y crea el mundo espiritual y moral mapuche.
}

Un caso interesante, analizado por Bacigalupo (2008-2009, 2016), es el de la machi Francisca Kolipí, figura de reputación ambigua, considerada por algunos kalku o bruja. Tras la muerte, los miembros de su grupo familiar y comunitario emprenden un ejercicio de olvido sistemático para permitir la partida de su espíritu. Años más tarde, los mismos, recuperan su memoria y revaloran su figura, en la esperanza de que su püllu encarne en una nueva machi. 
La comunicación con los ancestros también se verifica a través de las oraciones. Es común que las personas se dirijan a los püllu de sus antepasados para que los ayuden en el logro de sus objetivos, lo cual supone la atribución a estos de una agencia espiritual. En los sectores de Lago Neltume y Punahue, precordillera de la comuna de Panguipulli, la importancia de la comunicación con los difuntos se manifiesta en el uso de árboles como espacio de emplazamiento espiritual (Rojas 2016a y 2016b). En un lugar escogido de antemano -uno de cuyos requisitos es la presencia de un árbol-, se deposita el ataúd en el tránsito al cementerio luego del velorio y antes del entierro. Allí, en lo sustantivo, se llevan a cabo dos prácticas: un discurso de carácter exhortativo centrado en expulsar al espíritu del plano de los humanos (amulpullun) y el sacrificio de una gallina ritual (kare kare) abocado a propiciar a los antepasados para que lo integren de buena manera en su plano. El árbol finalmente se desempeñará como morada del espíritu. En adelante los deudos se dirigirán hasta este árbol para comunicarse con los difuntos, en una interacción que no se interrumpe con la muerte.

Los principios que organizan la sociabilidad en esta vida trascienden los límites de su temporalidad. Así lo muestra el testimonio del cautivo Francisco de Almendras (en Ovalle 1646) quien relata las solicitudes del cacique Luis Quitolibeun al momento de la muerte de su hijo:

\footnotetext{
Ya es llegada la hora de vuestra muerte, hijo mío; esforzaos para que lleguéis a la otra vida con bien, y mirad, hijo mío, que llegando a la otra parte del mar, sembréis, luego que lleguéis, muchas habas, alverjas y maíz, papas, trigo y cebada y de todas las legumbres. Y hace una casa grande para que quepamos todos en ella, porque vuestra madre y yo estamos más ya de muerte que de vida, por la mucha edad que tenemos, que presto estaremos por allá con vos.
}

Según Guevara (1908: 280), al entrar en la otra vida los recientemente fallecidos son recibidos por sus parientes "con fiesta suntuosa, en la que el licor se bebe en abundancia". Los padres se reúnen con sus hermanos e hijos, los esposos vuelven a la convivencialidad.

En la narrativa mapuche es frecuente que los muertos sean los encargados de anunciar a sus familiares la proximidad de la muerte o se encarguen de venir a buscarlos en este trance. No obstante, la fuerza de los vínculos sociales hace que los espíritus también regresen a la tierra a visitar a sus deudos. Una de sus figuraciones más conspicuas es la de püllomen, la mosca de la carne (Rosales 1877 [1674]; Augusta y FraunhaeusI 1910; Cooper 1946). Así lo registra la 'canción del enamorado' (Koessler-Illg 1962: 28):

\footnotetext{
...Cuando me fui a Ka Mapu estaba triste, / pero he vuelto por ti; por ti he vuelto hermana. / De la uen pillan vengo, de la boca de un volcán vine/ para verte hermana, hermana querida, para guiarte. Recuerdo y lloro.

Como muerto te saludo, como püllomeñ vengo, ay hermana. / De noche he llegado a esta tierra, como ánima llegué. / Como ánima he regresado, / he regresado como püllomeñ. Ya la gente no habla de mi. / Por amor volví hermana; por tu amor he venido. / Por eso he vuelto, como püllomeñ he vuelto; / del trolol mamüll salí. / Y volaré sobre tu cabeza; acariciándola he de rozarte la cabeza hermana.
}

La presencia de las moscas azules en las rogativas es observada con el respeto que se debe a los espíritus. Del mismo modo sucede en el espacio centro andino, donde los ancestros transfigurados en moscas reciben el nombre de chiririnka (Cipolletti 1984). Su llegada es recibida como señal confirmatoria en la celebración del Día de Todas las Almas (Bastien 1996) cuando se levantan mesas rituales y se prepara una docena de platos, uno por cada mes, para alimentar los espíritus de los difuntos. 


\section{Discusión de los criterios de demarcación}

Clastres (1987 [1980]) plantea, de un modo paradigmático, la demarcación entre los modelos de ancestralidad "amazónico" y "andino". Su trabajo ofrece una serie de criterios que permiten establecer la disyunción entre las concepciones de la muerte prevalecientes en estas áreas. De acuerdo al autor, en primer término, en el mundo amazónico se debe distinguir entre culto a los ancestros y culto a los muertos, puesto que el pensamiento indígena discrimina entre difuntos antiguos y recientes. Los ancestros son anónimos, se sitúan en un tiempo primordial y se encuentran separados por una brecha generacional. A éstos se los honra como fuente de la vida social. A los muertos, por el contrario, se los considera peligrosos, perniciosos y agresivos. En consecuencia, los ritos funerarios buscan eliminar su presencia y borrarlos de la memoria. En contraste, en el mundo andino, la vida social se sostiene tanto sobre el culto a los ancestros como a los difuntos.

Según Clastres, la diferencia en los modelos de ancestralidad se expresa en procedimientos fúnebres contrastantes. Los pueblos de la selva procuran desprenderse y eliminar los restos corporales, a diferencia de los pueblos andinos que emplean cementerios para depositarlos. En los primeros, las personas extinguen sus relaciones con los muertos, en los segundos los difuntos continúan participando de la vida social y constituyen una fuente de benevolencia y prosperidad.

Debe advertirse que la validez de estas generalizaciones ha sido relativizada especialmente respecto del modelo de ancestralidad amazónico (Chaumeil 1992,1997; Mouriès 2014). Las revisiones etnográficas han mostrado que en esta área la relación con los muertos muestra una diversidad que cuestiona la existencia de este patrón general. No obstante, igualmente es claro que la exclusión de los espíritus de los difuntos es una pauta prevaleciente entre un número importante de culturas amazónicas. Por lo mismo, más que el emplazamiento geográfico, lo relevante para nosotros son las diferencias en los modelos de representaciones escatológicas que especifican el destino e importancia de los ancestros en la vida social. El Ilamado "modelo amazónico" correspondería a una pauta de exclusión de los muertos en la vida social; el "andino", de culto a los difuntos. En el primer caso, los espíritus de los antepasados se encuentran ausentes de la vida cotidiana de las personas, en el segundo son parte de ellas como entidades dotadas de agencia benéfica.

Para nosotros, el emplazamiento de esta discusión se inicia con la pregunta sobre la adscripción de la cultura mapuche en relación con estos sistemas de representaciones. En esta perspectiva, los criterios de demarcación propuestos por Clastres resultan interesantes. Si nos atenemos a ellos, nos parece clara la adscripción mapuche al patrón andino. Dillehay (2017: 39) documenta a partir del siglo XII el uso de monumentos funerarios denominados kuel, "destinados a mantener a los ancestros en el mundo de los vivos". El uso continuado de cementerios, como el que informa el registro arqueológico (Berdichewsky y Calvo 1971) es un indicador de ancestralización. Los procesos de memorialización de los muertos se expresan aquí en el uso de instalaciones escultóricas denominadas chemamüll, personas de madera, en estos espacios (Moesbach 1936 [1930], Bullock 1964). Ellos se ubican, habitualmente, en las proximidades de las canchas rituales 
de ngillatun. En el área lelfunche de Lago Ranco y Río Bueno, donde hemos realizado nuestro trabajo etnográfico, ello se expresa de manera ejemplar en los complejos sagrados de Maihue Carimallín y Nolguehue, donde los eltun constituyen espacios colindantes a los renü en los que habitan ancestros míticos y próximos a los campos de rogativas.

Los lepün, como se denominan en estas comunidades a los ngillatun, rituales sacrificiales corporativos de solicitud y acción de gracias, se conciben aquí como una instancia de interacción entre ancestros míticos, antepasados reales y miembros de las congregaciones. Los espíritus son también participantes relevantes en las rogativas de San Juan de la Costa y en las comunidades de La Paz, Calafquén y Lago Neltume y Punahue donde se les propicia a través de visitas a los cementerios. El registro etnográfico muestra que, al menos en una parte del mundo mapuche, sigue vigente la pauta ancestral de culto a los antepasados.

En contraste, Di Giminiani (2012) observa la ausencia de ritos en los cementerios como indicador de la falta de vigencia del culto a los ancestros. Omite mencionar la asistencia a los eltun durante el Día de Todas las Almas, cuando los mapuche comparten alimentos con sus muertos. Se puede argumentar que éste no constituye un ritual propio de su cultura. Esta celebración, inscrita igualmente en la tradición cristiana, corresponde a un momento de conjunción astronómica, en el que la Cruz del Sur se encuentra en el acimut, es decir, en el punto más cercano al plano del horizonte. En el mundo andino dicen que la chakana, el puente, como se denomina a esta constelación, se encuentra tendido, para que bajen las almas. Se trata de un momento ritualizado desde tiempos prehispánicos en esta área, cuya tradición se proyecta en el presente entre quechuas y aymaras. Aunque no se tratase de un ritual propio mapuche, se trata de una práctica apropiada, en la que los comuneros interactúan con sus difuntos, a los que suelen llevar carne, vino y cigarros, y desarrollar prácticas de comensalidad asociadas. En el marco de esta visita a los cementerios, hemos observado la formulación de solicitudes a los difuntos, para enfrentar dificultades y necesidades de los concurrentes. A éstos se los considera entidades espirituales provistas de agencia, por ello, en caso de acontecer ciertos sueños (pewma), los familiares deben acudir a la tumba o al descanso de quien se haya manifestado con objeto de regular sus relaciones (Rojas 2013).

Course y Di Giminiani destacan que la funebria mapuche difiere del clásico modelo etnológico elaborado por Hertz (1990 [1907]) sobre la base de la documentación disponible de los Dayaks del archipiélago Malayo. De acuerdo a este patrón ritual, el paso desde la sociedad humana a la sociedad de los espíritus está marcado por una etapa de desintegración del individuo y luego por una fase de síntesis. En el caso mapuche, esta primera fase, de análisis o descomposición de los componentes de la persona, no se encuentra simbolizada en el ritual de exequias. No obstante, el propio Hertz advierte que su modelo admite variantes y excepciones. Éste no se propone como una teoría que aspire a la generalización (Huntington y Metcalf 1979), como lo parece entender Di Giminiani (2012: 130), quien insiste en la importancia canónica del modelo, donde la disolución de la individualidad es condición para la disposición de una forma genérica de poder ancestral. 
En contraste, como muestra Course (2007, 2011, 2017), el discurso fúnebre mapuche, conocido como amulpüllun, busca más bien la integración de los componentes de la persona. A través de este procedimiento sostenemos- se hace al muerto emprender el camino hacia la morada de los espíritus, produciendo un ancestro que mantiene su identidad individualizada, pero que igualmente puede ser invocado de manera genérica como 'pu alwe', 'pu am' o 'püllu'. Esta persistencia de la identidad se advierte, igualmente, en rituales de almas en el mundo andino, cuando los deudos esperan su regreso.

\begin{tabular}{|c|c|c|}
\hline \multicolumn{3}{|c|}{ Afinidades entre patrones de ancestralidad y representaciones escatológicas andinas y mapuche } \\
\hline Rasgos culturales & Andinos & Mapuche \\
\hline Patrones de entierro & $\begin{array}{l}\text { Cementerios comunitarios fijos, } \\
\text { presencia de formas monumentales. }\end{array}$ & $\begin{array}{l}\text { Formas monumentales (kuel), cementerios } \\
\text { comunitarios (eltuwe), en algunos casos } \\
\text { articulados con otros espacios rituales } \\
\text { como ngillatuwe }\end{array}$ \\
\hline $\begin{array}{l}\text { Representaciones materiales } \\
\text { de los espíritus }\end{array}$ & $\begin{array}{l}\text { Uso frecuente de imágenes e íconos. } \\
\text { Creencia de la encarnación de los } \\
\text { espíritus en insectos, especialmente } \\
\text { en forma de moscas (chiririnka). }\end{array}$ & $\begin{array}{l}\text { Representaciones antropomorfas labradas } \\
\text { en madera dispuestas en los cementerios } \\
\text { (chemamüll). } \\
\text { Creencia de la manifestación de los } \\
\text { espíritus en forma de moscas (püllomen). }\end{array}$ \\
\hline Concepciones de la muerte & $\begin{array}{l}\text { Paso a otra vida, con carácter } \\
\text { progresivo, representada como un } \\
\text { viaje hasta la morada de ultratumba. }\end{array}$ & $\begin{array}{l}\text { Paso a otra vida, con carácter progresivo, } \\
\text { representada como un viaje hasta la morada } \\
\text { de ultratumba. }\end{array}$ \\
\hline Paisajes escatológicos & $\begin{array}{l}\text { Sistemas de variantes en las } \\
\text { representaciones de la morada } \\
\text { de ultratumba, que incluyen islas } \\
\text { marinas, volcanes y el cielo, con } \\
\text { manifestaciones locales definidas. }\end{array}$ & $\begin{array}{l}\text { Sistemas de variantes en las } \\
\text { representaciones de la morada de } \\
\text { ultratumba, que incluyen islas marinas, } \\
\text { volcanes y el cielo, con manifestaciones } \\
\text { locales definidas. }\end{array}$ \\
\hline Agencia espiritual & $\begin{array}{l}\text { Espíritus provistos de capacidad } \\
\text { afectar el destino de sus parientes } \\
\text { vivos de un modo benéfico o punitivo. }\end{array}$ & $\begin{array}{l}\text { Espíritus provistos de capacidad afectar el } \\
\text { destino de sus parientes vivos de un modo } \\
\text { benéfico o punitivo. }\end{array}$ \\
\hline Patrones rituales & $\begin{array}{l}\text { Culto a los ancestros en ceremonias } \\
\text { comunitarias. } \\
\text { Ritual de día de muertos. }\end{array}$ & $\begin{array}{l}\text { Persistencia, en algunos sectores, del culto } \\
\text { a los ancestros en ceremonias comunitarias. } \\
\text { Patrones ritualizados de invocación y } \\
\text { alimentación de los espíritus. } \\
\text { Ritual de día de muertos }\end{array}$ \\
\hline Sociabilidad con los ancestros & $\begin{array}{l}\text { Consideración de los ancestros como } \\
\text { integrantes de las comunidades. } \\
\text { Memoria activa a los difuntos. } \\
\text { Comunicación con los ancestros a } \\
\text { través de sueños. }\end{array}$ & $\begin{array}{l}\text { Consideración, en algunos sectores, de } \\
\text { los ancestros como integrantes de las } \\
\text { congregaciones rituales. } \\
\text { Memoria activa de los difuntos. } \\
\text { Comunicación con los ancestros a través de } \\
\text { sueños. }\end{array}$ \\
\hline
\end{tabular}




\section{Conclusiones}

Los antecedentes expuestos muestran que la cultura mapuche cultiva la memoria a sus muertos, expresada en diversas manifestaciones. El emplazamiento localizado de los cuerpos hace de los cementerios hitos topográficos demarcados y destacados del paisaje, hacia donde se transita siguiendo una pauta que se transmite de una generación a otra. En ellos se instauran los chemamüll, figuras antropomorfas labradas en madera que representan materialmente a los difuntos. Su memoria se activa en actos de propiciación a los espíritus, en oraciones y solicitudes dirigidas a los muertos a quienes se considera dotados de agencia, en la práctica de comunicación a través de los sueños y en las conversaciones cotidianas al interior de la familia. A través de estos ejercicios de anamnesis, los muertos continúan participando de la vida social. La memoria a los muertos asume un carácter normativo cuya transgresión se considera fuente potencial de desgracias y castigos. Los espíritus viven en el recuerdo de sus deudos de manera personalizada. Con la partida sucesiva a la otra vida de sus familiares, progresivamente se transforman de antepasados individualizados en ancestros abstractos.

La importancia atribuida al devenir de las personas tras la muerte se expresa en la diversidad de términos lingüísticos que designan las formas y manifestaciones del espíritu, entre las que destacan las voces alwe, am, püllu. Ellas se registran de modo frecuente en los discursos rituales dirigidos a la comunicación con los antepasados. Del mismo modo hemos sido testigos de su presencia en las conversaciones cotidianas de autoridades ancestrales políticas y religiosas que buscan en los sueños la guía de los püllu. Los espíritus ancestrales son aquí referentes fundamentales de las tramas de comunicación a través de las que se toman decisiones y se orienta la acción.

La importancia que se atribuye al destino de las personas tras su deceso se expresa en la diversidad de representaciones escatológicas que sitúan la morada de ultratumba en los volcanes, al otro lado del mar o en el cielo. Estas concepciones no se presentan necesariamente en forma difusa, como afirma Course, sino como un sistema de variantes cuyas alternativas se encuentran, en diversas áreas, como modelos bien definidos. Por ejemplo, en el espacio cordillerano de la región det Los Ríos, el Volcán Villarrica o Rukapillan es considerado la morada de los espíritus. En el espacio de los llanos o lelfunche de esta misma región, los cementerios se emplazan en relación con el curso de las aguas que conducen a los espíritus en dirección al mar.

No obstante, debe advertirse que el pensamiento mapuche muestra un carácter relacional y modular, de modo que las opciones no necesariamente rivalizan, sino que se integran. Por lo mismo, el emplazamiento de los espíritus suele asumir un carácter multisituado, localizándolos no sólo en la morada de ultratumba, sino en los caminos que conducen desde y hacia el otro mundo. En Calafquén, por ejemplo, se considera que los espíritus residen en el volcán, pero también en las canchas de rogativa. En Lago Neltume y Punahue, se los identifica con los árboles situados en los descansos fúnebres, pese a que su residencia es el volcán. Los cementerios son lugares donde se los visita, alimenta y propicia, aunque estos no sean su destino final. 
La muerte en la cultura mapuche, al igual que en el mundo andino, asume un carácter progresivo. El espíritu debe emprender un viaje largo y peligroso para llegar a la morada de ultratumba. La congregación fúnebre de sus consanguíneos y afines es fundamental para asegurar su partida. Los ejercicios de memoria son un medio para ayudarlos en su viaje. El carácter articulante y sentido integrador de la funebria mapuche asegura la persistencia en la identidad social del espíritu que mantendrá sus vínculos con su grupo de pertenencia. En las áreas donde hemos desarrollado nuestro trabajo etnográfico, ello se manifiesta en las rogativas comunitarias, que se consideran un espacio de convivencia e interacción entre las personas, los espíritus de los antepasados reales y míticos, los espíritus de la naturaleza y la divinidad.

Del mismo modo, resulta evidente que la vigencia de este sistema de representaciones ha ido retrocediendo en el marco general de los procesos de aculturación religiosa (Moulian 2012). Un dato elocuente es la sostenida disminución del culto a los ancestros en rogativas del área de la Araucanía. Ello es expresión de los procesos de cambio que dan paso desde la organización en base a patrilinajes a formas de organización social ampliada multilinaje. En este marco, la mediación simbólica de los ancestros reales deja de ser funcional. En su reemplazo se consolida el culto a los espíritus de la naturaleza o la propiciación directa de la divinidad. Por lo mismo, no discutimos la validez etnográfica de las afirmaciones de Course y Di Giminiani quienes señalan la falta del culto a los antepasados en las comunidades donde realizaron sus investigaciones. Lo que cuestionamos es la generalización de sus resultados al conjunto de la cultura mapuche. Su diseño metodológico no lo permite. Los datos procedentes de nuestro trabajo de campo contradicen sus afirmaciones.

El registro etnohistórico informa de modo nítido la precedencia del culto a los muertos (Rosales 1877 [1674]; Latcham 1924; Bacigalupo 1986; Véliz 1996) expuesto en los discursos y acciones de los ngenpin, ngillatun kamañ y miembros de las congregaciones rituales. El análisis interdisciplinario de los emplazamientos reche (Adán 2014) y de los paisajes simbólicos (Dillehay 2017) lo ratifican. El uso de los kuel como monumentos fúnebres de uso ritual comunitario es un ejemplo de la profundidad histórica del culto a los ancestros.

Allí donde esta pauta se ha perdido en los rituales comunitarios, la relación con los espíritus se mantiene vigente en la vida de las personas. Ello se manifiesta en las oraciones y solicitudes individualizadas de los deudos y en los sueños. En términos de la ontología mapuche, los espíritus velan por las necesidades de sus familiares y pueden informarles su destino. Los mapuche confían en que al final de la vida se reunirán nuevamente con sus seres queridos en la morada de ultratumba, donde volverán a brindar ritualmente. Por lo mismo, el olvido se considera una transgresión a las obligaciones para con los muertos, que expone a una sanción sobrenatural.

Los antecedentes expuestos muestran un modelo de ancestralidad fuerte, afín al patrón andino de culto a los antepasados. Por la continuidad de la sociabilidad entre vivos y muertos; por la agencia que se les atribuye a estos; por la persistencia de manifestaciones del culto a los ancestros en las rogativas; por la profundidad y extensión de los antecedentes etnohistóricos, arqueológicos y lingüísticos del 
mismo; y por las formas de memorialización de los difuntos, esta adscripción es clara. Junto a ello, el análisis de las representaciones escatológicas del destino de ultratumba muestra el registro de un sistema de variantes similares al mundo andino. Este correlato no implica necesariamente vínculos de origen, pero sí muestra una cotradición: la extensión a lo largo del cordón cordillerano de concepciones similares del destino humano tras la muerte.

Por último, es importante señalar que no pretendemos dar por clausurado el debate con este artículo. Entre los desafíos que quedan pendientes se encuentran la delimitación de las áreas donde se mantienen vigentes los patrones de culto y comensalidad con los ancestros y el estudio diacrónico de las pautas rituales donde ellas no permanecen activas. Entre los resultados previsibles debe considerarse la variabilidad histórica en las manifestaciones de esta institución. Ha de tenerse en cuenta que el culto a los ancestros es solo uno de los componentes del complejo sistema religioso cosmovisionario mapuchecompuesto, igualmente, por el culto alos espíritus de la naturaleza y a divinidades múltiples, que muchas veces resultan predominantes y se encuentran más desarrollados que el primero. Por lo mismo, nuestro foco de atención en este artículo no se reduce al estudio de la invocación a los espíritus en el espacio ceremonial comunitario, sino aborda la relación con los ancestros en una perspectiva más amplia. Ésta incluye diversas prácticas culturales y formas de comunicación en las que se expresa y define el modelo de la ancestralidad mapuche.

\section{Bibliografía}

Abercrombie, T. 1998. Pathways of memory and power: Ethnography and history among Andean people. Madison: University of Wisconsin Press.

Adán, L. 2014. Los reche-mapuche a través de sus sistemas de asentamiento (s. XV-XVII). Tesis para optar al grado de Doctora en Historia, mención Etnohistoria. Santiago: Universidad de Chile.

Alderman, J. 2015. "Mountains as actors in the Bolivian Andes: The interrelationship between politics and ritual in the kallawaya ayllus". The Unfamiliar 5 (1-2): 32-45.

Alvarado, M. y Mera, R. 2004. "Estética del paisaje y reconstrucción arqueológica. El caso de la región del Calafquén". Chungará (Volumen Especial): 559-568.

Allen, C. 1982. "Body and soul in Quechua thought", Journal of Latin American Lore 8 (2): 179-196.

Amory, D. 2013. Las principales leyendas, mitos, historias y cuentos de Chile. Bélgica: Edgar Adrien.

Arguedas, J. M. 2012. "Puquio, una cultura en proceso de cambio". En Obra Antropológica. Lima: Editorial Horizonte, tomo 4: 245-291.

Arnold, D. y Hasthorf, Ch. 2008. Heads of state: Icons, power, and politics in the Ancient and Modern Andes. Walnut Creek: Left Coast Press.

Arriaga, J. 1621. Extirpación de la idolatría del Piru. Lima:
Geronymo de Contreras Impresor

Augusta, F. 1916: Diccionario araucano-español y españolaraucano, tomo primero, Santiago: Imprenta Universitaria.

Augusta, F. y Fraunhaeusl, S. 1910. Lecturas araucanas. Valdivia: Imprenta Prefectura Apostólica.

Bacigalupo, A. 1986. Definición, evolución e interrelaciones de tres conceptos mapuches: Pillan, Ngüenechen y wekufe. Tesis de Licenciatura en Historia. Santiago: Pontificia Universidad Católica de Chile.

Bacigalupo, A. 2007. Shamans of the foye tree: Gender power, and healing among Chilean Mapuche. Austin: University of Texas Press.

Bacigalupo, A. 2008-2009. "Vida, muerte y renacimiento de una machi mapuche. Recordar, desrecordar y la transformación deliberada de una memoria". Historia Indígena 11: 7-31.

Bacigalupo, A. 2016. "Thunder machi: Making history with Mapuche spirits in Chile and Patagonia. Austin: University of Texas Press.

Bacigalupo, A.1995a. "El rol sacerdotal de la machi en los valles centrales de la Araucanía”. En Parker, C. (dir.), ¿Modernización o sabiduría en tierra mapuche? Santiago: San Pablo, 61-95.

Bacigalupo, A. 1995b. "Imágenes de diversidad y consenso: la cosmovisión mapuche a través de tres machi”. Aisthesis 28: 
121-141.

Bascopé, P. 2001. "El sentido de la muerte en la cosmovisión andina: El caso de los valles andino de Cochabamba, Bolivia". Chungará 33 (2): 271-277.

Bastien, J. 1996. La montaña del cóndor: metáfora y ritual en un ayllu andino. La Paz: Hisbol.

Bengoa, J. 2003. Historia de los antiguos mapuches del sur. Desde antes de la llegada de los españoles hasta las paces de Quilín. Santiago: Editorial Catalonia.

Berdichewsky, B. y Calvo, M. 1971. "Excavaciones en cementerios indígenas de la region de Calafquén". Actas del VI Congreso de Arqueología Chilena, 529-558.

Boccara, G. 2007 [1998]. Los Vencedores. Historia del Pueblo Mapuche en la Época Colonial. San Pedro de Atacama: Ocho Libros \& IIAM/U. de Chile.

Bourget, S. 1994. "El mar y la muerte en la iconografía mochica". En Uceda, S. y Mujica, E. (eds.), Moche: Propuestas y perspectivas. Lima: Universidad Nacional de Trujillo, 425-447.

Bovisio, M. 2012. "Devenir en ancestro: muerte y ancestralidad en el N.O. argentino prehispánico". Disponible en https://www. academia.edu/6345763/Devenir_en_ancestro_2012 (consultada: enero de 2018).

Bullock, D. 1964. "Cruces y figuras de madera en cementerios". Revista Universitaria de la Universidad Católica de Chile 49: 165167.

Calvo, M. 1987. Secretos y tradiciones mapuche. Santiago: Editorial Andrés Bello.

Carneiro da Cunha, M. 1978. Os muertos e os outros: Uma análise do sistema funerario e da noção de pessoa entre os índios Krahó. São Paulo: Editora Huicitec.

Catrileo, M. 1995. Diccionario lingüístico-etnográfico de la lengua mapuche. Santiago: Editorial Andrés Bello.

Cecconi, A. 2013. "Cuando las almas cuentan la guerra: Sueños, apariciones y visitas de los desaparecidos en la región de Ayacucho". En del Pino, P y Yezer, C. (eds.) Las formas del recuerdo: etnografías de la violencia política en el Perú. Lima: IEP e IFEA.

Chaumeil, J. 1992. "La vida larga. Inmortalidad y ancestralidad en la Amazonia". En Cipolletti, M. y Langdon, E. (eds.), La muerte y el más allá en las culturas indígenas latinoamericanas. Quito: Abya-Yala, 113-124.

Chaumeil, J. 1997. "Entre la memoria y el olvido: observaciones sobre ritos funerarios de tierras bajas de América del Sur". Boletín de Arqueología de la Pontificia Universidad Católica del Perú 1: 207-232.

Cipolletti, M. 1984. "El motivo de Orfeo y el viaje al reino de los muertos en América del Sur". Indiana 9: 421-431.

Citarella, L. (ed.). 1995. Medicinas y Culturas en la Araucanía. Santiago: Editorial Sudamericana.

Clastres, H. 1968. "Rites funéraires Guayaki". Journal de la Société des Américanistes 57: 63-72.

Clastres, P. 1987 [1980]. Investigaciones en antropología política. México: Gedisa.
Cooper, J. 1946. "The Araucanians". Handbook of South American Indians: Vol. II, Steward, J. (ed.). Washington: The Smithsonian Institution.

Course, M. 2007. "Death, biography, and the Mapuche person". Ethnos 72 (1): 77-101

Course, M. 2011. Becoming Mapuche: Culture and person in indigenous Chile. Champain: University of Illinois Press.

Course, M. 2017. Mapuche ñi mognen. Persona y sociedad en la vida mapuche rural. Santiago: CIIR \& Pehuén.

Cruz, J., Cortés, J. y Yufla, C. 2013. El universo de nuestros abuelos: Proyecto de etnoastronomía atacameña. San Pedro de Atacama: IIAM\&ALMA.

Curaqueo, D. 1989-1990. "Creencias religiosas mapuche. Revisión crítica de interpretaciones vigentes". Revista Chilena de Antropología 8: 27-33.

D'Altroy, T. 2016. "Killing mummies: On inka epistemology and imperial power". En Renfrew, C., Boyd, M. y Morley, I. (eds.) Death rituals, social order and the archaeology of immortality in the Ancient World. Cambridge: Cambridge University Press, 404-422.

Delgado, R. 2001. "El mundo de los muertos en los relatos mapuches". Historia, Antropología y Fuentes Orales 26: 109-137.

Descola, P. 2012. Más allá de la naturaleza y la cultura. Buenos Aires: Amorrortu Editores.

Di Giminiani, P. 2012. Tierras ancestrales, disputas contemporáneas: pertenencia y demandas territoriales en la sociedad mapuche ancestral. Santiago: Ediciones Universidad Católica.

Dillehay, T. 1990. Araucanía: presente y pasado. Santiago: Editorial Andrés Bello.

Dillehay, T. 2011. Monumentos, imperios y resistencia en los Andes: El sistema de gobierno mapuche y las narrativas rituales. Santiago: Ocho Libros Editores, Qillca y Vanderbilt University.

Dillehay, T. 2017. La organización política temprana de los mapuche. Materialidad y patriarcado andino. Santiago: Pehuén.

Doyle, M.1988. Ancestor cult and burial ritual in seventeenth and eighteenth century Central Peru. Ph.D. dissertation. Los Angeles: University of California.

Duviols, P. 1976. "Une symbolisme andine du doble: le litomorphose de l'ancestre". Actas del XLII Congreso de Americanistas 4: 7-31.

Eekchout, P. y Owens, L. 2015. Funerary practices and models in the Ancient Andes: The return of the living dead. New York: Cambridge University Press.

Erize, E. 1960. Diccionario comentado mapuche-español. Buenos Aires: Universidad Nacional del Sur.

Faron, L. 1961. "On ancestor propiciation among Mapuche of central Chile". American Anthropologist 63 (4): 824-830.

Faron, L. 1968. The Mapuche Indians of Chile. Case Studies in Cultural Anthropology. New York: Holt, Rinehart and Winston.

Faron, L. 1997 [1964]. Antupaiñamko: moral y ritual mapuche. Santiago: Ediciones Mundo.

Febrés, A. 1765. Arte de la lengua general del reino de Chile. Lima: Calle de la Encarnación. 
Fernández, G. 2007. "Un difunto en el altar: los niños difuntos y su relevancia ceremonial en los andes".

Flores, J.A. y Abad, L. (coords.), Etnografías de la muerte y las culturas en América Latina. Cuenca: Ediciones Universidad Castilla-La Mancha.

Fernández, J. 2009. "El simbolismos y misticismo del lobo de mar en la antigua costa norte del Perú". Flumen 5 (1): 3-19.

Foerster, R. 2018 [2003]. ¿Pactos de sumisión o actos de rebelión? Una aproximación histórica y antropológica a los mapuche de la costa de Arauco, Chile. Santiago: Pehuén.

Foerster, R. 1995. Introducción a la religiosidad mapuche. Santiago: Editorial Universitaria.

Foerster, R. 1985. Vida religiosa de los huilliche de San Juan de la Costa. Santiago: Ediciones Rehue.

Foerster, R. y Gundermann, H. 1989. "Religiosidad mapuche contemporánea: elementos introductorios". En Hidalgo, J. et al. (eds.), Culturas de Chile: Etnografía, sociedades indígenas contemporáneas y su ideología. Santiago: Editorial Andrés Bello.

Fu, R. 2016. "Las estrellas a través de las araucarias: la etnoastronomía mapuche-pewenche". Boletín del Museo de Arte Precolombino 21: 81-100.

García, C. 2009. "El mundo de los muertos en la cosmovisión centroandina". Gaceta Antropológica 25 (2). Disponible en http:// hdl.handle.net/10481/6893

Gil, F. 2002. "Donde los muertos no mueren. Culto a los antepasados y reproducción social andina. Una discusión orientada a los manejos del tiempo y el espacio". Anales del Museo de América 10: 53-83.

Gordon, 1978. "Urna y canoa funeraria. Una sepultura doble excavada en Padre Las Casas. Prov. de Cautín, IX Región, Chile". Revista Chilena de Antropología 1: 61-80.

Grebe, M. 1975. "Taxonomía de las enfermedades mapuche". Nueva Época 2: 27-39.

Grebe, M. 1986. "Algunos paralelismos en los sistemas de creencias mapuches: Los espíritus del agua y de la montaña". CUHSO 2: 143-154.

Grebe, M., Pacheco, S. y Segura, J. 1972. "Cosmovisión mapuche". Cuadernos de Realidad Nacional 14, 46-73.

Greenway, Ch. 1988. Hungry earth and vengeful stars: soul loss and identity in the Peruvian Andes. Social Science \& Medicine 47 (8): 993-1004.

Guaman Poma de Ayala, F. 1980. Nueva coronica y buen gobierno. Caracas: Biblioteca Ayacucho.

Guevara, T. 1908. Psicolojía del pueblo araucano. Santiago: Imprenta Cervantes.

Guevara, T. 1911. Folklore Araucano. Santiago: Imprenta Cervantes.

Guillén, S. 2004. "Artificial mummies from the Andes". Collegium Antropologicum 28 (2): 141-157.

Hardacre, H. 1987. "Ancestors: Ancestors worship". En Jones. L. (ed.), Encyclopedia of Religion. Detroit: Thompson Gale, 1: 320-325.

Harris, O.1982. "The dead and the devils among the Bolivian
Laymi”. En Bloch, M. y Parry, J. Death and the regeneration of life. Cambridge: Cambridge University Press.

Hastorf, Ch. 2003a. "Andean luxury foods: Special food for the ancestors, deities and the élite". Antiquity 77 (297): 545-554.

Hastorf, Ch. 2003b. "Community with the ancestors: ceremonies and social memory in the Middle Formative at Chiripa, Bolivia". Journal of Anthropological Archaeology 22: 305-332.

Havestadt, Bernardi, 1883 [1777]. Chiledúgu sive tractatus linguae chilensis. Vol II, edición de Julio Platzmann. Leipzig: B. G. Teubner.

Hertz, R. 1990 [1907]. "Contribución a un estudio sobre la representación colectiva de la muerte". En Hertz, R., La muerte y la mano derecha. Madrid: Alianza, 15-102.

Hilger, I. 1957. Araucanian child life and its cultural background. Washington: Smithsonian Institution.

Housse, E. 1940. Epopeya India. Santiago: Zig-Zag.

Huntington, R. y Metcalf, P. 1979. Celebrations of death: The anthropology of mortuary rituals. Cambridge: Cambridge University Press.

Isbell, W. 1997. Mummies and mortuary monuments: A postprocessual prehistory of Central Andean social organization. Austin: University of Texas Press.

Insoll, T. 2011. "Ancestor cults". En Insoll, T. (ed.), Oxford handbook of the archaeology of ritual and religion. Oxford: Oxford University Press, 1043-1058.

Jodelet, D. 1984. "La representación social: fenómenos, concepto y teoría". En Moscovici, S. (comp.), Psicología social. vol 2: 469-494.

Kaulicke, P. 2001. Memoria y muerte en el antiguos Perú. Lima: Fondo Editorial Universidad Católica del Perú.

Kemper, C. 1997. "Dos ejemplos del pensamiento andino nolineal: los zorros de Arguedas y la illa andina". An-thropologica 15: 195-216.

Koessler-llg, B. 1962. Tradiciones araucanas, Tomo I. La Plata: Instituto de Filología, Facultad de Humanidades y Ciencias de la Educación, Universidad Nacional de la Plata, Argentina.

Koessler-llg, B. 2000 [1954]. Cuentan los araucanos. Buenos Aires: Nuevo Extrema.

Koessler-llg., B. 2006. Cuenta el pueblo mapuche (Volumen I). Santiago: Editorial Mare Nostrum.

Kuramochi, Y. y Huisca, R. 1997 Cultura mapuche: relatos, rituales y ceremonias. Quito: Abya-Yala.

Kuramochi, Y. y Nass, J. 1989. "Kamarikun: valoración de la tradición y causalidad". Actas de la Lengua y Literatura Mapuche 3: 25-56.

La Riva. 2017. "Soñando en los Andes. Experiencia onírica y concepción del cuerpo-persona”. Revista Andina 55: 125-155.

Latcham, R. 1924. La organización social y las creencias religiosas de los antiguos araucanos. Santiago: Imprenta Cervantes.

Lau, G. 2002. "Festing and ancestor veneration at Chinchawas, north higlands af Ancash, Perú". Latin American Antiquity 13 (3) 279-304. 
Lau, George. 2008. "Ancestor images in the Andes". En Silverman, H. and Isbell, W. (eds) Handbook of South American Archaeology. New York: Springer, 1027-1045.

Lau, George. 2016. "Different kinds of dead: Presencing Andean expired beings". En Renfrew, C; Boyd, M. y Morley, I. (eds.). Death rituals, social order and the archaeology of immortality in the Ancient World. Cambridge: Cambridge University Press. 168-186.

Long, Ch. 1987. "Ancestors: mythic ancestors". En Jones, L. (ed.), Encyclopedia of religion. Detroit: Thompson Gale, 1: 325-327.

Lotman, J. y Uspenski, B. 1979. "Sobre el mecanismo semiótico de la cultura". En Lotman, I. y Escuela de Tartu, Semiótica de la Cultura. Madrid: Cátedra, 67-92.

Makowski, K. 2000. "Las divinidades en la iconografía mochica". En Los dioses del antiguo Perú. Lima: Banco de Crédito del Perú, 137-175.

Marileo, A. 1995. "Mundo mapuche". En Citarella, L. (comp.), Medicinas y culturas en la Araucanía. Santiago: Editorial Sudamericana, 91-107.

Melville, T. 2016 [1976]. La naturaleza del poder social mapuche. Santiago: Pehuén.

Millahueique, C. 2003. "Comentarios sobre patrimonio cultural: Una aproximación al patrimonio indígena”. LIDER 32: 98103.

Millones, L. 2010. Después de la muerte. Voces del limbo y del infierno en el territorio andino. Lima: Fondo Editorial del Congreso del Perú.

Millones, L. y Kapsoli, W. 2001. La memoria de los ancestros. Lima: Editorial Universitaria de la Universidad Ricardo Palma.

Moesbach, W. 1936 [1930]. Vida y costumbres de los indígenas araucanos en la segunda mitad del siglo XIX. Santiago: Imprenta Cervantes.

Moesbach, W. 1980. Diccionario español-mapuche. Buenos Aires: Sirigna Libros.

Molina, I. 1795. Compendio de la historia civil del reyno de Chile: Segunda Parte. Madrid: Imprenta de Sancha.

Montecino, S. 1997. "El río de lágrimas". Anales de la Universidad de Chile, sexta serie. Disponible en http://web.uchile. cl/publicaciones/anales/6/estudios6.htm (consultado: enero de 2018).

Montecino, S., Philippi, L., Artigas, D., y Obach, A. 2003. Mitos de Chile: diccionario de magias, seres y encantos. Santiago: Editorial Sudamericana.

Moore, J. 2004. "The social basis of sacred spaces in the Prehispanic Andes: Ritual landscapes of the dead in Chimú and Inka societies". Journal of Archaeological Method and Theory 11 (1): 83-124.

Moscovici, S. 1979. El psicoanálisis, su imagen y su público. Buenos Aires: Editorial Huemul.

Moulian, R. 2005. Tiempo de lepün: una etnografía visual del ngillatun williche. Valdivia: Programa Orígenes \& Universidad Austral de Chile.

Moulian, R. 2008. Ngen rüpu / El camino del Ngen: un trabajo de arqueología de los símbolos y etnografía multimedia. Valdivia: Fondo de la Cultura y de las Artes \& Universidad Austral de Chile. Moulian, R. 2012. Metamorfosis ritual: desde el ngillatun al culto pentecostal. Valdivia: Kultrún \& Universidad Austral de Chile.

Moulian, R. y Espinoza, P. 2014. "Pneumatología, paisaje y culto: patrones andinos en los procesos de ancestralización de la cultura mapuche emplazados en la naturaleza". Chungará 46 (4): 637-650.

Moulian, R. y Garrido, C. 2015. "Etnopoéticas del umbral: el simbolismo del arco en la cultura mapuche williche y sus recurrencias en los sistemas cosmovisionarios andinos". Estudios Atacameños 51: 207-229.

Moulian, R. y Valdés, C. 2001. Abuelito Huenteao: mito y ritual: Documental etnográfico. Valdivia: Fondo de la Cultura y las Artes.

Mouriès, T. 2014. "¿Con o sin ancestros? Vigencia de lo ancestral en la Amazonía peruana." Anthropologica 32: 14-40.

Nakashima, L. 1989. Dream interpretation among the Mapuche indians of Chile. Doctoral dissertation. Los Angeles: University of California.

Nakashima, L. 1992. "Sueños de muerte y transformación de los mapuche de Chile". En La muerte y el más allá en las culturas indígenas latinoamericanas. Quito: Abya-Yala, 37-50.

Negro, S. 1996. "La persistencia de la visión andina de la muerte en el virreinato del Perú". Anthropologica 14: 121-141.

Ñanculef, J. 2016. Tayiñ mapuche kimun: epistemología mapuche-sabiduría y conocimientos. Santiago: Universidad de Chile.

Nielsen, A. 2008. "Materiality of ancestors: Chullpas and social memory in the late prehispanic history of South Andes". En Mills, B. and Walter, W. (eds). Memory work: Archaeologies of material practices. School of American Research Press. Santa Fe, 207-232.

Norton, K. 2013. "Identifying mortuary ritual and ancestor veneration: A spatial analysis of the tombs at Hualcayán". UW-L Journal of Undergraduate Research XVI. file:///C:/ Desktop/Pueblos\%200riginarios \%20\%20septiembre\%20 2018/Mundo\%20andino/Andinos,\%20muerte/Norgon. Kate. Archaeology.pdf (Consultado diciembre 2018).

Ovalle, A. 1646. Histórica relación del reyno de Chile. Roma: Francisco Caballo.

Peters, A. 2014. "Dressing the leader, dressing the ancestor: The longue durée in South Central Andes". Textile Society of America Symposium Proceedings 945. http://digitalcommons.unl. edu/tsaconf/945 (Consultado diciembre 2018).

Pozo, G. y Canio, M. 2014. Wenumapu. Astronomía y cosmología mapuche. Santiago: Ocho libros Editores.

Quidel, J. 2017. "Ta iña mapu piken: güxamyegen ta mapu". En Becerra, R. y Llanquinao, G. (eds.). Mapun kimün. Relaciones mapunche entre persona, tiempo y espacio. Santiago: Ocho libros editores.

Quidel, J. 2012. La idea de Dios y Diablo en el discurso ritual mapuche. Tesis de Maestría en Antropología Social. Campinas: Universidade Estadual de Campinas. 
Quidel, J. y Pérez, P. 2001. "Elaboración del duelo en cada cultura". En Pérez, P. (ed.), Muerte y desaparición forzada en la Araucanía: una aproximación étnica. Temuco: Ediciones Universidad Católica de Temuco.

Ramírez, Susan. 2005. To feed and be fed: The cosmological bases of authority and identity in the Andes Satanford: Stanford University Press.

Robin, V. 2008. Miroirs de l' autre vie: Practiques rituelles et discours sur les morts dans les Andes de Cuzco (Pérou). Nenterre: Société d' Ethnologie.

Rojas, P. 2013. Persona / Paisaje. El Descanso, un Rito Fúnebre Mapuche (documental etnográfico). Valdivia. Coordinación de Extensión Facultad de Filosofía y Humanidades, Universidad Austral de Chile.

Rojas, P. 2016a. "El rito fúnebre mapuche del descanso: una muda ontológica al árbol de los ancestros". Chungará 48 (4): 657678.

Rojas, P. 2016b. Los descansos en el proceso mortuorio mapuche: de la muda ontológica a la morada de los ancestros. Valdivia: Consejo Nacional de la Cultura y las Artes \& Texto Contexto.

Rojas, P., Mellado, M., García, C. 2015. "La cámara en el trabajo de campo: usos metodológicos y éticos del registro audiovisual en el mundo mapuche cordillerano". Revista Chilena de Antropología Visual 26: 138-146.

Rosales, D. 1877. Historia General de el Reyno de Chile: Flandes Indiano. Tomo I. Valparaíso: Imprenta El Mercurio.

Salomon, F. 1995. "The beautiful grandparents". En Dillehay, T. (ed.), Tombs for the living. Andean mortuary practices. Washington D.C.: Dumbarton Oaks, 315-354.

Sánchez, R. 2017. La muerte y el mundo subterráneo en los Andes. Lima: Editorial Bisonte.

Sanfuentes, S. 1925. "Memoria sobre el estado de las misiones en esta provincia en 1846, pasada al gobierno por el Intendente de la misma don Salvador Sanfuentes". En Bauer, K. (comp.), Valdivia antes de la inmigración. Valdivia: Imprenta Borneck.

Schindler, H. 1996. "Amullpüllün: un rito funerario de los mapuche chilenos". Actas de la Lengua y Literatura Mapuche 7: 165-180.

Shimada, I. y Fitzsimmons, J. (eds). 2015. Living with dead in the Andes. Tucson: The University of Arizona Press.

Silva, O. 1980. Culturas y pueblos de chile prehispánico. Santiago: Editorial Salesiana.
Skewes, J. y Guerra, D. 2016. "Sobre árboles, volcanes y lagos: Algunos giros ontológicos para comprender la geografía mapuche cordillerana del sur de Chile". Intersecciones en Antropología 17: 63-76.

Slater, F. 1986. "Relatos mapuches sobre los vivos y los muertos". Aisthesis 7 (WENULEUFU. Camino al Cielo): 23-42.

Taylor, A. 1993. "Remembering to forget: Identity, mourning and memory among the Jivaro". Man 28 (4): 653-678.

Titiev, M. 1951. Araucanian culture in transition. Ann Arbor: University of Michigan Press.

Titiev, M. 1969. "Book reviews: The Mapuche Indians of Chile". American Anthropologist 71: 743- 744.

Urton, G. 2006. El cruce de rumbos de cielo y la tierra. Centro Bartolomé de Las Casas.

Valderrama, R. y Escalante, C. 1980. "Apu Qorpuna (visión del mundo de los muertos en la comunidad de Awkinmarka)". Debates de Antropología 5: 233-269.

Valdivia, L. 1887 [1606]: Arte y gramática general de la lengva que corre en todo el reyno de Chile con vn confessionario $y$ vocabvlario, edición de Julio Platzmann, Leipzig: B. G. Teubner.

van Kessel, J (comp). 1999. Los vivos y los muertos. Duelo y ritual mortuorio en los Andes. Iquique: IECTA.

Vargas, N. 2013. "Los sueños y las almas para el hombre andino". Revista de Estudios Cotidianos 3: 354-375.

Vásquez, M. 1988. El Viaje al Reino de los Muertos en el Relato Mítico Mapuche. Tesis para optar al título de Profesor de Estado en Castellano. Valdivia: Universidad Austral de Chile.

Velasco, M. 2014. "Building on the ancestors: Mortuary structures and extended agency in the Late Prehispanic Colca Valley, Peru". Cambridge Archaeological Journal 24 (3): 453-465.

Véliz, C. 1996. La Muerte Araucana o una Modificación de la Vida. Tesis para optar al grado de Licenciado en Historia. Santiago: Universidad Católica de Chile.

Werwlosky, Z. 1987. "Eschatology". En Jones, L. (ed.), Encyclopedia of Religion. Detroit: Thompson Gale, 4: 2833-2836.

Yanai, T. 2004. "Notas sobre el «pillañ»: En torno a E. Böning, El concepto de pillán entre los mapuches". Disponible en http:// archive.is/aDO4C (consultado: noviembre de 2017).

Yaya, I. 2015. "Sovereign bodies: Ancestor cult and state legitimacy among the Incas". History and Anthropology 26 (5): 639-660.

Zúñiga, F. 2004: Mapudungun: El habla mapuhe. Santiago: Centro de Estudios Públicos. 
